\title{
Developing Sustainable Ultra High Strength Concrete Mixtures Using Spent Foundry Sand
}

\author{
Anthony Torres ${ }^{1}$, Federico Aguayo ${ }^{1}$, and Srinivas Allena ${ }^{2}$ \\ 1. Department of Engineering Technology, Texas State University, San Marcos 78666, Texas, USA \\ 2. Department of Civil Engineering, Cleveland State University, Cleveland 44115, Ohio, USA
}

\begin{abstract}
This study presents the development of ultra high strength concrete (UHSC) that has been made more sustainable by using both local materials from central Texas and spent foundry sand (FS) from the metal casting industry, which has also been obtained locally. This study first describes various trial mixtures tested as well as the specimen preparation techniques investigated that led to the final UHSC-FS mixtures. The developed mixtures were proportioned with local constituents to increase the sustainable impact of the material by reducing emissions due to shipping as well as making UHSC more affordable to a wider variety of applications. The final mixture design constituents were: river sand, locally available type I/II cement, silica fume, and spent FS, which was obtained from a local steel casting company. Multiple variables were investigated, such as the aggregate type and size, concrete age (7, 14, and 28-days), the curing regimen, and the water-to-cement ratio $(\mathrm{w} / \mathrm{cm})$ to optimize a UHSC mixture that used local materials and FS. This systematic development revealed that heat curing the specimens in a water bath at $50{ }^{\circ} \mathrm{C}\left(122{ }^{\circ} \mathrm{F}\right)$ after demolding and then dry curing at $200{ }^{\circ} \mathrm{C}$ $\left(392^{\circ} \mathrm{F}\right.$ ) two days before testing with a w/cm of 0.20 at 28 -days produced the highest compressive strengths. Once an optimum UHSC mixture was identified a partial replacement of the fine aggregate with FS was completed at $10 \%, 20 \%$, and $30 \%$. The results showed an increase of compressive strength performance at $10 \%$ replacement, followed by no change at $20 \%$, and finally a slight decrease at $30 \%$. Developing this innovative material with local materials and FS ultimately produces a novel sustainable construction material, reduces the costs, and produces mechanical performance similar to prepackaged, commercially, available construction building materials.
\end{abstract}

Key words: High strength concrete, sustainability, recycled concrete aggregate, local products, construction materials.

\section{Introduction}

Green construction through sustainable building materials has been an important aspect in the concrete and construction field in the last decade. Using waste products in concrete production is beneficial environmentally and economically: environmentally by replacing a portion of the virgin components with waste materials and environmentally by clean disposal of waste materials. Combining these benefits with locally obtained materials ultimately increases these factors. As Texas is one of the largest producers of cement and aggregate in the nation, it is beneficial to develop a novel sustainable construction building material that utilizes locally available materials. Combining this factor with the reuse of spent foundry

Corresponding author: Anthony Torres, Ph.D., research fields: concrete and cement materials. sand (FS) from the metal casting industry can drastically increase the sustainable impact of concrete production. Spent FS is a by-product of ferrous and non-ferrous metal casting industries primarily consisting of high quality silica sand. Approximately 6-10 million tons of this waste is produced annually by the foundry industry in the United States alone. Spent FS, when used as partial replacement of fine aggregate in concrete, has shown to improve the mechanical properties of concrete [1-5]. Existing studies, however, limit their focus to conventional concrete and few reports on the use in higher strength concretes.

In the past years, improvements have been occurring in concrete and construction material technology. Sustainable use of supplementary materials and revolutionary developments in chemical admixtures has facilitated improvements in the mechanical properties of concrete materials. Such mechanical 
properties that have drastically been impacted are the strength, density, and the modulus of concrete materials [1-2]. Through these developments higher strength concrete materials have emerged, known as ultra high strength concrete (UHSC). However, these chemical and material developments have consistently changed the definition of high strength concrete (HSC). The American Concrete Institute (ACI) has defined UHSC that cannot always be achieved routinely, using conventional constituents and normal mixing, placing, and curing practice [6]. In the 1950s, concrete with a compressive strength of $34 \mathrm{MPa}$ (5,000 psi) was considered high strength [2]. Today, high-strength concrete is defined as concrete with a specified compressive strength of $55 \mathrm{MPa}(8,000 \mathrm{psi})$ or higher [6]. In many markets today, concrete having a specified compressive strength in excess of $69 \mathrm{MPa}(10,000 \mathrm{psi})$ is routinely produced on a daily basis [6]. However, UHSC is expected to have compressive strengths in excess of $120 \mathrm{MPa}(17,400 \mathrm{psi})$ [7-8] at 28-days. HSC and UHSC themselves are considered a sustainable construction building material due to the high requirement of silica fume and fly ash, both of which are waste products from other industries, which provides beneficial properties development of concrete [7-8]. Not only does UHSC utilize a high percentage of fly ash and/or silica fume, the high strength requirement results in a higher specific strength of the material. The specific strength of a material is the ratio of the strength to its density. Since the density of UHSC does not increase significantly to that of conventional concrete, but the strength does, the specific strength is much higher than that of conventional concrete. This aspect impacts sustainable construction through decreased transportation cost and emissions as a smaller structural member can be produced out of UHSC, which will require less fuel and produce less carbon emissions during shipping.

In the present research, a multiple UHSC trial mixtures were made to attain $120 \mathrm{MPa}(17,400 \mathrm{psi})$ compressive strengths at 28-day or higher. These mixtures were developed based off of the literature and slightly modified to meet locally available constituents and reproduced in the laboratory. This iterative trial process was completed in order to determine an optimum UHSC mixture that used high amounts of local materials, was feasible to produce, met the compressive strength requirements, and could easily accommodate FS replacement of the natural virgin sand.

\section{Literature Review}

\subsection{Background Information}

UHSC is traditionally composed of cement, coarse aggregate that is much smaller than conventional coarse aggregate $\leq 9.5 \mathrm{~mm}$ (0.375 in.) [6-8], fine aggregate, supplemental cementitious materials (SCM) such as silica fume, fly ash, granulated ground blast furnace slag (GGBFS), and quartz powder, fibers, and a water reducing admixture known as a high range water reducing admixture (HRWRA). When used in optimum dosages, the HRWRA reduces the water-to-cement (or water-to-cementitious) ratio while improving the workability (viscosity) of the concrete. The addition of the SCMs enhances the mechanical properties of the cement paste by producing secondary hydrates, filling voids, and enhancing rheology [6-8]. Due to the burgeoning large structure industry, there are more and more requirements for higher strength concrete. UHSC has been in development since the mid 1950's and many researchers are still investigating the optimum and most efficient manner to produce this material [6-8]. However, modern construction practices are moving towards sustainable construction through lower cost and sustainable materials, therefore, UHSC improvements should also be focused on becoming more sustainable and more affordable.

In recent years there has been extensive research conducted to study the effect of FS in concrete production. Prabhu, G. G. et al. [9] categorized the various ways and means of reusing foundry waste. The categorization is based off of elemental components 
classification achieved through chemical analyses and particle size. The research conducted by Prabhu, G. G. et al. (from a cast iron plant) showed that the main source of foundry waste is molding sand $(360 \mathrm{t} / \mathrm{d})$. The remaining are from molds from dust abatement/molding lines $(150 \mathrm{t} / \mathrm{d})$, furnace and ladle slags $(100 \mathrm{t} / \mathrm{d})$, powdered sands from shakeout and slotting $(90 \mathrm{t} / \mathrm{d})$, broken cores $(50 \mathrm{t} / \mathrm{d})$, powders from core thermal regeneration plants $(6 \mathrm{t} / \mathrm{d})$ and exhaust lime from desulphurization processes (6t/d) [9]. This categorization is critical to the current study because it gives a better understanding of unique chemistry of different foundry waste. In terms of particle size classification, foundry waste residue above $0.6 \mathrm{~mm}$ (0.02 in.) can be reused in core production, because of their metallic content [8]. The authors also postulated that the fraction of the foundry waste with particle sizes that range between $0.1 \mathrm{~mm}(0.004 \mathrm{in}$.) and $0.6 \mathrm{~mm}$ (0.02 in.) can be reused after undergoing regeneration treatment, and the fraction between $0.1 \mathrm{~mm}(0.004 \mathrm{in}$.) and $0.0025 \mathrm{~mm}$ (9.8E-5 in.) can be used as SCM in the concrete industry. The results of the chemical test conducted by the authors showed that, due to the high silica content of FS and its inert and fine particulate nature, FS is suitable for concrete production as either an SCM or fine aggregate replacement. Prabhu, G. G. et al. [9] were able to show the economic viability, and the blueprint for recycling FS from metal casting plants.

Siddique et al. [1-2] have shown the potential of using spent FS in the production of concrete. Their experimental investigation showed how different replacement levels of FS as fine aggregate, affect the mechanical properties of conventional concrete. The mechanical properties investigated were: compressive strength, splitting-tensile strength, flexural strength and modulus of elasticity. The values of the investigated properties were determined at different ages of concrete samples ( 28 days, 56 days, 91 days and 365 days). The authors categorized their experiment at 3 replacement level percentages $(10 \%$,
$20 \%$ and $30 \%$ ). Siddique et al. [1-2] discuss that based off of binder system content, FS can be classified into; clay bonded FS otherwise known as green sand, and chemically bonded FS. This classification is centered on physical and environmental factors. Previous researches have also shown that the naturally occurring components such as high quality silica sand (85-95\%), bentonite clay (4-10\%) and carbonaceous additive (4-10\%), make clay bonded FS ideal for use as replacement material. This is largely because of high silica content and also the adhesive properties and fine particulate nature of its clay content. The results showed that all specimens attained a marginally significant increase in compressive strength at 28 days of curing. The control mixture showed compressive strength value of $28.5 \mathrm{MPa}(4,133 \mathrm{psi})$. The $20 \%$ and $30 \%$ replacement samples showed an increase in compressive strength with results of $30.0 \mathrm{MPa}(4,351$ psi) and $31.3 \mathrm{MPa}(4,540 \mathrm{psi})$ respectively. Quantitatively, test samples 20\% and 30\% replacement showed compressive strength increases of $5.2 \%$ and $9.8 \%$ respectively. The consistency in the results of all tested concrete mixtures showed that FS can positively impact the compressive strength of concrete. The authors postulated that this could be attributed to the fineness of FS. This particular quality can enormously influence the density of concrete matrix. Splitting tensile strength, flexural strength and elasticity modulus test results showed a lot of similarity to the compressive strength result. At 28 days of curing, concrete mixtures $0 \%, 10 \%, 20 \%$, and $30 \%$ showed splitting tensile strength values of $2.75 \mathrm{MPa}$ (400 psi), 2.85 $\mathrm{MPa}$ (413 psi), 2.9 $\mathrm{MPa}$ (420 psi) and 3.0 $\mathrm{MPa}$ (435 psi) respectively. Concrete mixtures $0 \%, 10 \%$, $20 \%$, and $30 \%$ achieved flexural strength of $3.41 \mathrm{MPa}$ (494 psi), 4.0 MPa (580 psi), 4.1 MPa (594 psi) and $4.18 \mathrm{MPa}(606 \mathrm{psi})$ respectively. Concrete mixtures $0 \%$, $10 \%, 20 \%$, and $30 \%$ also showed elasticity of modulus values of $25.1 \mathrm{GPa}(3,640 \mathrm{ksi}), 26.8 \mathrm{GPa}(3,887 \mathrm{ksi})$, $27.60 \mathrm{GPa}(4,003 \mathrm{ksi})$ and $28.4 \mathrm{GPa}(4,119 \mathrm{ksi})$. This marginally significant increase in tensile strength, 
flexural strength, and elastic modulus was directly proportional to increase in curing age. The authors were able to experimentally show that an increase in FS as replacement for fine aggregate has a positive impact on the mechanical properties of concrete. Various other authors have shown similar results [10-13].

\subsection{Sustainability}

This study focuses on two aspects of sustainable construction building materials; local use of constituent materials and the use of recycled materials. A major concern in the production of UHSC is the high cost from shipping such materials as quartz dust, steel or specialty aggregates, and fibers. Most of these constituents are often shipped long distances and internationally in many cases, which increases the cost of the material. It should also be noted that due to the chemical interaction requirements of the silica fume and cement drastically increases the cost of commercially available, prepackaged, UHSC products [6-8]. The commercially available UHSC from prepackaged manufacturers uses expensive materials such as ground quartz and fibers that are not traditionally available locally, which increases the cost of the final product. Therefore, the present work focuses on developing UHSC mixtures using local materials so that HSC may be made more affordable to wide variety of construction applications. Using local products drastically decreases emissions associated with long shipping routes. The second focus of this study is producing UHSC with the inclusion of FS as partial replacement of virgin fine aggregate. Replacing virgin materials used in the production of HSC with recycled materials drastically increases the sustainable impact of the material. By using discarded waste material in new construction, the strain for new, virgin, materials is slightly alleviated while also minimizing the demand for landfill space. Additionally, the Leadership in Energy and Environmental Design (LEED) provides a material credit for using building materials or products that have been extracted, harvested or recovered, as well as manufactured, within 500 miles of the project site for a minimum of $10 \%$ or $20 \%$, based on cost, of the total material's value [14]. Therefore, using both local materials that make up $100 \%$ of the concrete product and using FS will count double for this LEED requirement.

\section{Experimental Program}

\subsection{Trial Mixtures and Materials}

As previously stated, multiple trail mixtures based off of the literature were investigated to determine the best option to allow for locally available materials and FS replacement that also meets the $120 \mathrm{MPa}(17,400$ psi) compressive strength requirements at 28 days. This study investigated the following locally available materials, which are readily available and easily attained. For coarse aggregate: limestone and pea gravel and for the fine aggregate: manufactured sand (limestone) and river sand were investigated. The base design mixtures were selected from the literature (three sources), but their constituents were changed to fit the locally available materials. For example, if the literature used a rounded coarse aggregate, then pea gravel was used as a substitution. If an angular coarse aggregate was used, then limestone was used. If the original mixture designed called for steel fibers, then those were excluded, as steel fibers are often not available locally, and are not in this instance. In all instances, the size of aggregates (and/or recommended gradation) was matched in the tested trial mixtures. Three base mixtures were selected from the literature that provides a general perspective on the various types of UHSC mixtures that can be produced. Some mixtures from the literature review suggest both coarse and fine aggregates, some suggests only fine aggregate, and some suggest very fine aggregate and high cement contents. The three selected attempts to provide insight to these three general types of UHSC mixtures. Table 1 outlines the tested trial mixtures.

As seen in Table 1, eight total trail mixtures were investigated across three sources. Burg et al. [15] 
Table 1 Trial mixture designs.

\begin{tabular}{|c|c|c|c|c|c|c|c|c|}
\hline $\begin{array}{l}\text { Source } \\
\text { Mixture ID }\end{array}$ & $\begin{array}{c}\text { Burg et al. [15] } \\
\text { Burg - LS/MS }\end{array}$ & $\begin{array}{c}\text { Burg et al. [15] } \\
\text { Burg - LS/RS }\end{array}$ & $\begin{array}{l}\text { Burg et al. [15] } \\
\text { Burg - PG/MS }\end{array}$ & $\begin{array}{c}\text { Burg et al. [15] } \\
\text { Burg - PG/RS }\end{array}$ & $\begin{array}{l}\text { Liu et al. [16] } \\
\text { Liu - RS }\end{array}$ & $\begin{array}{l}\text { Liu et al. [16] } \\
\text { Liu - MS }\end{array}$ & $\begin{array}{c}\text { Allena et al. [17] } \\
\text { Allena - RS }\end{array}$ & $\begin{array}{c}\text { Allena et al. [17] } \\
\text { Allena - MS }\end{array}$ \\
\hline \multicolumn{9}{|l|}{ Constituents $(\mathrm{kg} / \mathrm{m} 3)$} \\
\hline Cement (Type I/II) & 564 & 564 & 564 & 564 & 745 & 745 & 1500 & 1500 \\
\hline Silica Fume & 89 & 89 & 89 & 89 & 132 & 132 & 375 & 375 \\
\hline Limestone (LS) & 1068 & 1068 & - & - & - & - & - & - \\
\hline Pea Gravel (PG) & - & - & 1068 & 1068 & - & - & - & - \\
\hline Manufactured Sand (MS) & 593 & - & 593 & - & - & 1096 & - & 1347 \\
\hline River Sand (RS) & - & 593 & - & 593 & 1096 & - & 1347 & - \\
\hline Water & 124 & 124 & 124 & 124 & 162 & 162 & 375 & 375 \\
\hline HRWRA & 19.3 & 19.3 & 19.3 & 19.3 & 21.9 & 21.9 & 28.5 & 28.5 \\
\hline$w / c$ & 0.22 & 0.22 & 0.22 & 0.22 & 0.22 & 0.22 & 0.25 & 0.25 \\
\hline $\mathrm{w} / \mathrm{cm}$ & 0.19 & 0.19 & 0.19 & 0.19 & 0.18 & 0.18 & 0.20 & 0.20 \\
\hline
\end{tabular}

provided one source that contained a coarse and fine aggregate. Since the authors of this study have two coarse and two fine aggregates available, four combinations of the Burg mixture were investigated. As seen in Table 1, these mixtures were giving the designation of Burg-(coarse aggregate abbreviation)/(fine aggregate abbreviation): for example Burg-LS/MS refers to Limestone coarse aggregate and manufactured sand fine aggregate. In all Burg mixtures the coarse aggregate was less than 6.35 $\mathrm{mm}(0.25 \mathrm{in}$.) and the fine aggregate was well graded less than $3.35 \mathrm{~mm}(0.13 \mathrm{in}$.), which was matched by the locally available constituents. The second sourced UHSC was from Liu et al. [16], which only used fine aggregate and no coarse aggregate. According to Liu et al. [16] removing the coarse aggregate provides a more dense mixture that results in higher strength and performance. For the Liu mixtures the two locally available fine aggregates were used, which are well graded and less than $2.36 \mathrm{~mm}$ (0.093 in.). Lastly, two mixtures were produced based off of Allena et al. [17] that also only used fine aggregate, however, these mixtures sieved the fine aggregate passed the $\# 30$ sieve $0.60 \mathrm{~mm}(0.0236 \mathrm{in}$.), then washed on a \#200 sieve to remove any fine particulates. The rational by Allena et al. [17] for doing this was consistent with Liu et al. [16] in which finer particles produce a tighter and denser concrete network that can lead to higher strength and performance. All mixtures used the same cement (type I/II), silica fume, and HRWRA. All constituents were obtained from local providers within a 50-mile radius of San Marcos, TX. The aggregate was obtained from local quarries and sieved in the laboratory to achieve the required size and gradation. Table 2 shows the grain size distribution for both of the fine aggregates. Table 3 shows the chemical compositions of the type I/II Portland cement, silica fume, as well as the FS. Table 4 shows the physical properties of the coarse aggregates.

\subsection{Specimen Preparation}

The aggregates used in this study (coarse and fine) were sieved to obtain the desired size needed as described previously. The aggregates were then thoroughly washed over a \#200 sieve to remove any fine dust or debris. After washing, the aggregates were oven dried at $44{ }^{\circ} \mathrm{C}\left(110^{\circ} \mathrm{F}\right)$ to achieve a $0 \%$ moisture content.

The constituents of each mixture were then mixed for approximately 20 minutes using a laboratory pan mixer. The dry constituents (aggregate, cement, silica fume) were mixed for the first 2 minutes and then $75 \%$ of the water was added. After thorough mixing, the HRWRA was added with the remaining $25 \%$ of the water. This preparation method was used based off of the literature and experience [6-9, 13, 15-17]. 
Table 2 Grain size distribution for the river sand and manufactured sand.

\begin{tabular}{lll}
\hline Sieve No. & Sieve size, mm (in.) & Percentage passing \\
\hline 8 & $2.36(0.093)$ & 100 \\
16 & $1.18(0.0469)$ & 57.7 \\
30 & $0.60(0.0236)$ & 42.3 \\
50 & $0.30(0.0118)$ & 0.0 \\
\hline
\end{tabular}

Table 3 Chemical composition of cement and silica fume.

\begin{tabular}{llll}
\hline Compound & Cement & Silica fume & FS \\
\hline $\mathrm{SiO}_{2}$ & $21.5 \%$ & $95.8 \%$ & $94.1 \%$ \\
$\mathrm{Al}_{2} \mathrm{O}_{3}$ & $4.45 \%$ & $0.18 \%$ & $1.7 \%$ \\
$\mathrm{Fe}_{2} \mathrm{O}_{3}$ & $3.15 \%$ & $0.19 \%$ & $5.8 \%$ \\
$\mathrm{CaO}$ & $64.10 \%$ & $0.30 \%$ & $0.2 \%$ \\
$\mathrm{~K}_{2} \mathrm{O}$ & $\mathrm{NA}$ & $0.29 \%$ & $0 \%$ \\
$\mathrm{Na}$ & $0.52 \%$ (Equiv.) & $0.20 \%$ & $0 \%$ \\
$\mathrm{MgO}$ & $1.90 \%$ & $0.20 \%$ & $0 \%$ \\
$\mathrm{SO}_{3}$ & $2.89 \%$ & $0.11 \%$ & $0 \%$ \\
\hline
\end{tabular}

Table 4 Physical properties of limestone and pea gravel.

\begin{tabular}{lllll}
\hline Property & Standard & Unit & Limestone & Pea gravel \\
\hline Unit weight & ASTM C29 & $\mathrm{kg} / \mathrm{m}^{3}\left(\mathrm{lb} / \mathrm{ft}^{3}\right)$ & $1,442(90.0)$ & $1,586(99.0)$ \\
Water absorption & ASTM C127 & $\%$ & 2.98 & 1.45 \\
Bulk specific gravity $_{\text {ssd }}{ }^{\mathrm{a}}$ & ASTM C127 & - & 2.57 & 2.62 \\
Bulk specific gravity $_{\text {od }}$ & ASTM C127 & - & 2.51 & 2.60 \\
\hline
\end{tabular}

${ }^{a}$ ssd, saturated surface dry condition;

$\mathrm{b}$ od, oven dried condition.

\subsection{Curing Regimens}

In order to minimize as many variables as possible, two curing regimens were investigated completed on all trial mixtures. For the first regimen, concrete specimens were cured at room temperature $\left(23{ }^{\circ} \mathrm{C}(73\right.$ $\left.{ }^{\circ} \mathrm{F}\right)$ ) for the first 24 hours. Once the specimens were demolded, they were moist cured at $23^{\circ} \mathrm{C}\left(73^{\circ} \mathrm{F}\right)$ and a relative humidity of $98 \%$ until the day of testing. This curing method is a traditional curing method for conventional concrete as outline in ASTM C 192-15 [18].

The second curing regimen was taken from the literature, as it purported to be an effective curing method for UHSC [19]. This curing method also cured the samples at room temperature $23{ }^{\circ} \mathrm{C}\left(73^{\circ} \mathrm{F}\right)$ for the first 24 hours. After demolding, the specimens were heat cured in a water bath at $50^{\circ} \mathrm{C}\left(122^{\circ} \mathrm{F}\right)$ until 2 days prior to testing. At two days prior to testing, the specimens were removed from the water bath and dry cured at $200{ }^{\circ} \mathrm{C}\left(392^{\circ} \mathrm{F}\right)$. The above curing regimens were developed based on the study by Shaheen et al. [19].

\subsection{Compression Testing}

Compressive strength specimens were molded using 50.8-mm (2-in.) cube molds. Cubes specimens were used to avoid problems with end preparation of cylindrical specimens [2]. After the specimens were properly cured they were individually tested according to BS 12390-3-2009 [20]. The British Standard was used as it provides greater detail for testing hardened concrete cubes in compression than ASTM C 39-15a [20-21]. An average of three samples was tested per data point reported in the results section. Therefore, a minimum of nine specimens was produced per mixture per age in order to obtain a reportable value. 


\section{Results and Discussion}

The results of the compressive strength of the trail mixtures at all age range investigated using standard curing methods and using oven curing methods can be seen in Figs. 1 and 2 respectively.
As seen in Fig. 1, there are various results between the mixtures investigated. All results shown demonstrated as expected increase in strength with age. On first investigation the two Allena mixtures produced the highest results by far, with the

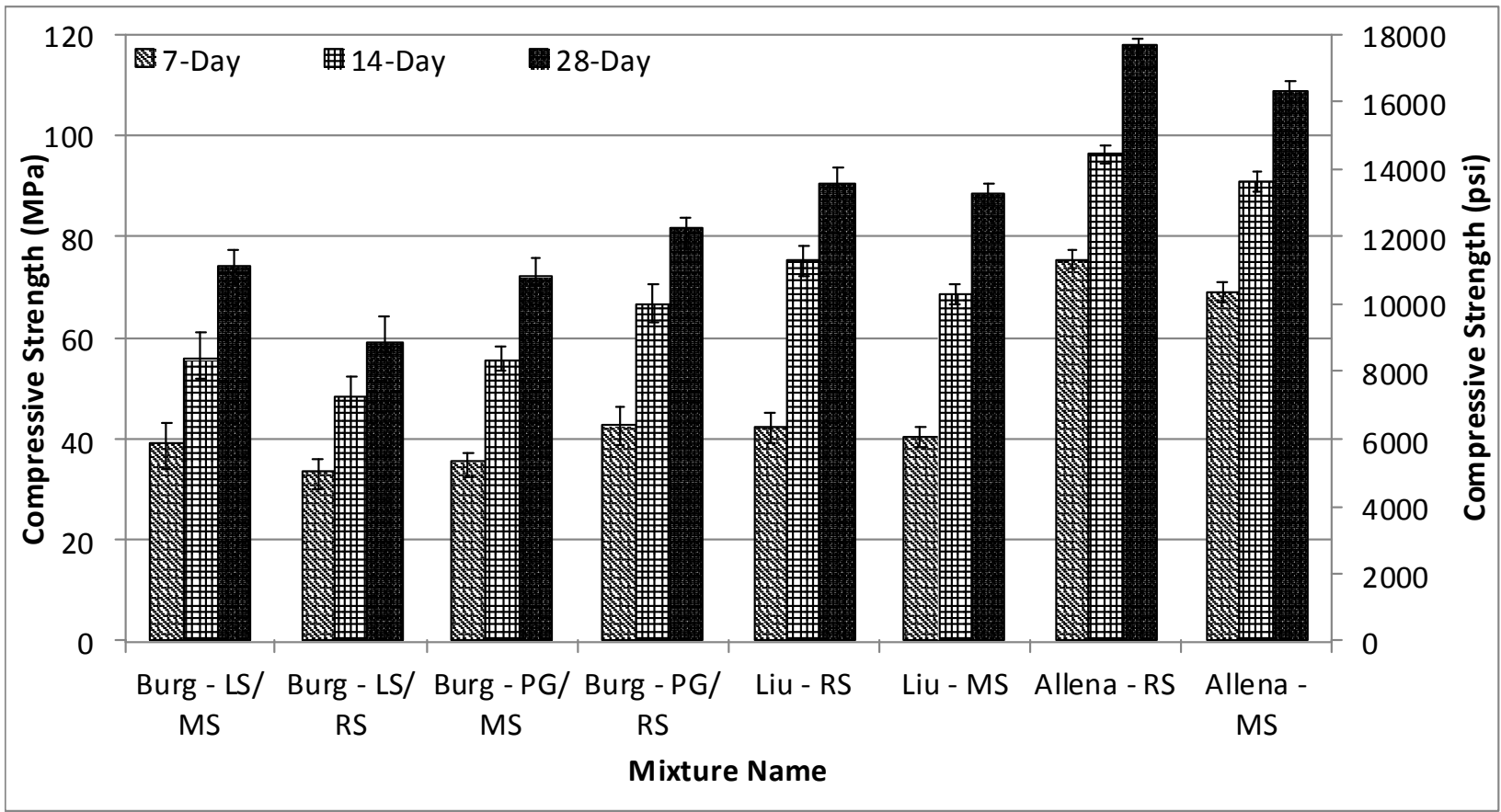

Fig. 1 Compressive strength results of trial mixtures using conventional curing methods.

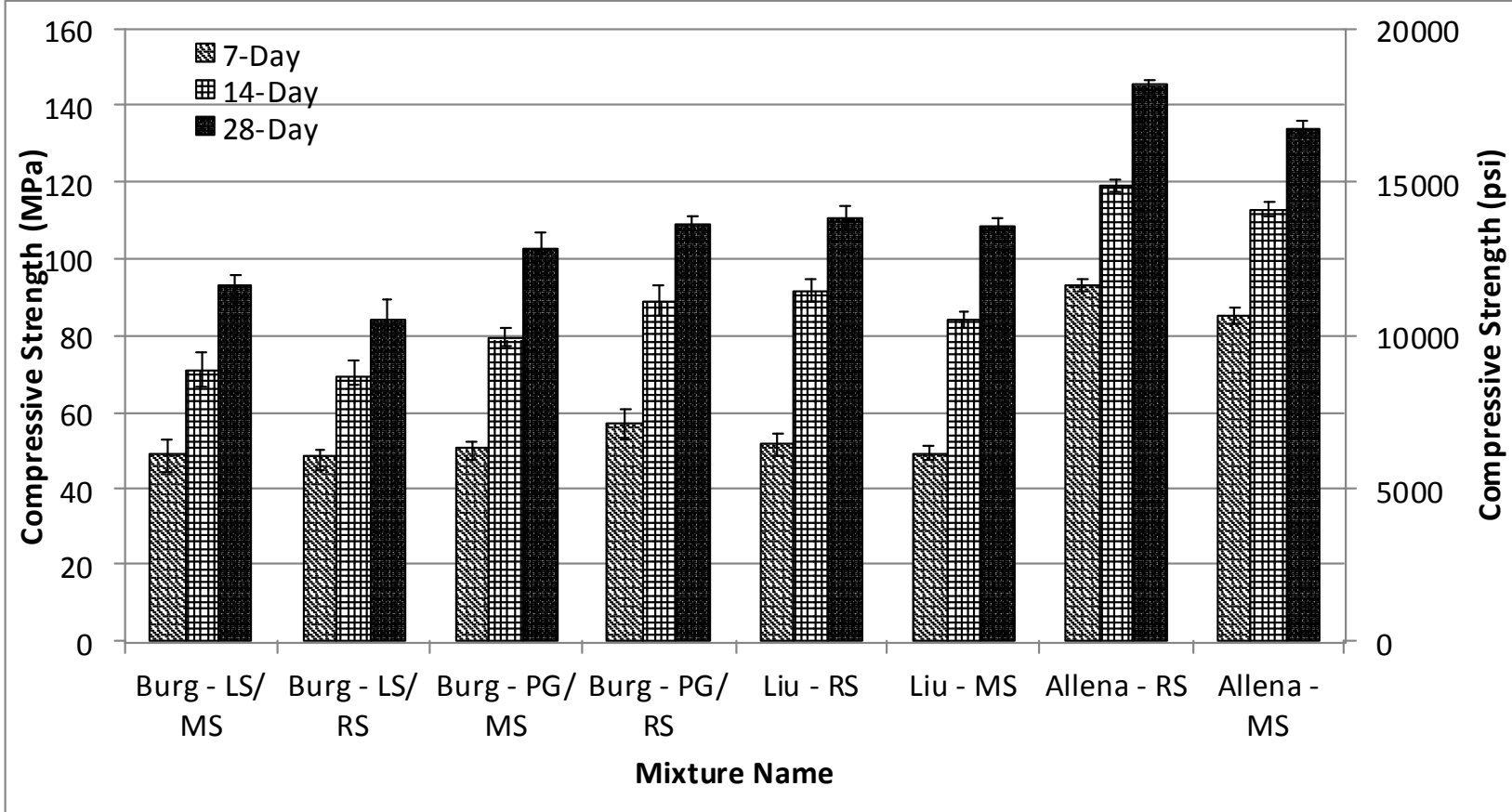

Fig. 2 Compressive strength results of trial mixtures using oven curing methods. 
one utilizing the river sand the highest overall. The lowest performing mixture was Burg-LS/RS using conventional curing methods. With traditional curing methods, it is noticed that none on the trial mixtures met the UHSC limit of $120 \mathrm{MPa}(17,400 \mathrm{psi})$ at 28 days. The only mixture that was close was the Allena-RS mixture that had a 28-day compressive strength of 118 MPa (17,050 psi). It can also be observed that the smaller the aggregate used in these mixtures, the higher the compressive strength performance. In other words, the Burg et al. [15] mixtures that used a coarse aggregate and a fine aggregate all had the lowest performing compressive strengths. Also, noticed is that these mixtures consequently had lower cement contents, and higher $\mathrm{w} / \mathrm{cm}$. The Liu et al. [16] mixtures used only fine aggregates with higher cement content and yielded higher compressive strengths. Lastly, the mixtures that had the highest amount of cement and smallest fine aggregate were the Allena et al. [17] mixtures, which produced the highest compressive strengths. As discussed in the literature review [6-8, 15-17], compressive strength performance is highly linked to high cement contents, small aggregates, high amounts of SCMs, and low w/cm. Of the three types of mixtures investigated, the Allena et al. [17] met these requirements, which resulted in the highest performing compressive strengths.

Once the oven curing method was introduced, as seen in Fig. 2, all mixtures exhibited a significant increase in strength. The curing method pushed Allena-RS and Allena-MS mixture above the UHSC requirements at an age of 28-days. All others came close, but were just shy of the mark. However, it should be stated that all mixtures are still considered HSC mixtures. To confirm that the Allena-RS mixture was the top performing mixture a student $t$-test was performed at a 95\% confidence level between Allena-RS and Allena-MS. The statistical analysis confirmed that Allena-RS was statistically significant. Based off of these results, the Allena-RS mixture was selected to become the UHSC mixture that would be modified to assess the impact of FS replacement of natural river sand. The same curing regimen will also be used on the mixtures containing FS. The new mixtures

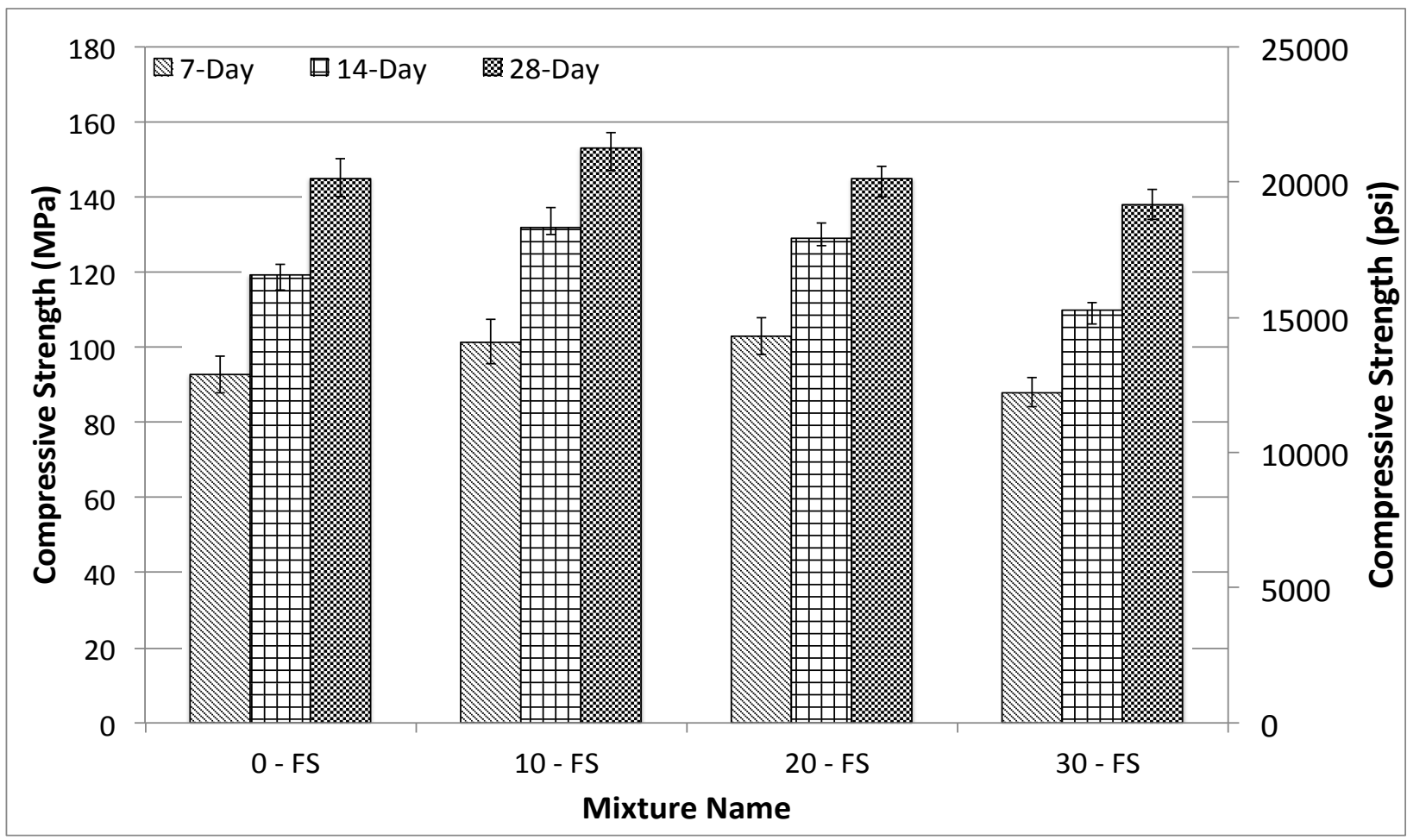

Fig. 3 Compressive strength results of UHSC-FS mixtures. 
containing $0 \%, 10 \%, 20 \%$, and $30 \% \mathrm{FS}$ replacement of natural sand by volume were prepared and testing in the exact same manner as the trial mixtures and the results can be seen in Fig. 3 .

As seen in Fig. 3, all UHSC mixtures that contain FS increased with age, as expected. Additionally, there was an increase in compressive strength performance at a $10 \%$ and $20 \% \mathrm{FS}$ replacement. There was a minor decrease in compressive strength performance at $30 \%$ FS replacement as well. These results are consistent with results found by the literature in which authors investigated the impact of FS on conventional concrete [1-5, 8-13]. According to the literature, due to the high silica content of FS, the material acts similar to other SCMs and provides fuel to grow cement hydrates and increase the density of the material [1-5]. A student $t$-test was also performed on these results to confirm their statistical significance. The $10 \%$ replacement mixtures had a statistical significance between the $0 \%$ mixture, however the $20 \%$ was not spastically significant between the $0 \%$ mixture. Despite the $20 \%$ mixture having higher compressive strengths than the $0 \%$ mixture, it was not statistically significant. Lastly, the $30 \%$ mixture did show statistical significance between the $0 \%$ mixture, with a small reduction in strength.

\section{Conclusions}

A novel sustainable construction building material has been developed that has high strength, uses recycled elements, and all the constituents were obtained locally. This study focused on developing a novel construction building material that can impact the sustainable construction building movement by not only developing an UHSC, but the UHSC has been made more sustainable by utilizing spent FS and all local constituents. This was completed by first producing various trail mixtures to determine how they perform when made with locally available materials. Once a top performing mixture was determined, the natural sand in the mixture was replaced with spent FS at $10 \%, 20 \%$, and $30 \%$ by volume replacement percentages. The results showed an increase of compressive strength performance at $10 \%$ replacement, followed by no change at $20 \%$, and finally a slight decrease at $30 \%$. These results were consistent with similar studies in which an increase is expected initially, followed by a decrease in performance. However, with UHSC, the decrease was noticed at an earlier replacement percentage than it does with conventional concrete. Despite this result, the overall goal of developing an UHSC material made entirely of local products and spent FS has been achieved and tested. The highest strength achieved by the UHSC-FS mixture was $153 \mathrm{MPa}(22,190 \mathrm{psi})$ at 28-days, with a FS replacement of $10 \%$.

\section{References}

[1] Siddique, R., Schutter, G., and Noumowe, A. 2009. "Effect of Used-FS on the Mechanical Properties of Concrete." Constr Build Mater 23: 976-80.

[2] Siddique, R., and Noumowe, A. 2008. "Utilization of Spent FS in Controlled Low-Strength Materials and Concrete." Resources, Conservation and Recycling 53: 27-35.

[3] Abichou, B. C., and Edil, T. 1998, "Database on Beneficial Reuse of Foundry By-Products." In Recycled Materials in Geotechnical Applications, edited by Vipulanandan, C., and Elton, D. Geotechnical Special Publication, ASCE, 210-3.

[4] MOEE. 1993. Spent Foundry Sand-Alternative Uses Study. Report prepared by John Emery Geotechnical Engineering Limited for Ontario Ministry of the Environment and Energy and the Canadian Foundry Association, Queen's Printer for Ontario.

[5] Prabhu, G. G., Jung, H. H., and Yun, Y. K. 2014. "Effects of Foundry Sand as a Fine Aggregate in Concrete Production." Elsevier, 514-21.

[6] ACI Committee 363. 2010. Report on High-Strength Concrete, ACI 363R-10. American Concrete Institute Committee 363, Farmington Hills, MI.

[7] ASTM Standard C1856/C1856-17. 2017. Standard Specification for Fabricating and Testing Specimens of Ultra-High Performance Concrete ASTM International, West Conshohocken, PA. DOI: 10.1856/C1856-17. www.astm.org.

[8] Dili, A. S., and Santhanam, M. 2004. "Investigations on Reactive Powder Concrete: A Developing Ultra High 
Strength Technology." The Indian Concrete Journal 74 (4): $33-8$.

[9] Bhardwaj, B., and Kumar, P. 2017. "Waste Foundry Sand in Concrete: A Review." Constr Build Mater 156: 661-74.

[10] Naik, T. R., Kraus, R. N., Chun, Y. M., Ramme, W. B., and Singh, S. S. 2003. "Properties of Field Manufactured Cast-Concrete Products Utilizing Recycled Materials." J Mater Civil Eng 15 (4): 400-7.

[11] Nwofor, T., and Ukpaka, C. 2016. "Assessment of Concrete Produced with Foundry Waste as Partial Replacement for River Sand." Journal of Civil Engineering Research, 1-6.

[12] Sohail, M., Wahab, A., and Khan Md, A. 2008. "A Study on the Mechanical Properties of Concrete by Replacing Sand with Waste Foundry Sand." International Journal of Emerging Technology and Advanced Engineering, 83-7.

[13] Torres, A., Bartlett, L., and Pilgrim, C. 2017. "Effect of Foundry Waste on the Mechanical Properties of Portland Cement Concrete." Construction and Building Materials 135: 674-81.

[14] Azhar, S., Carlton, W. A., Olsen, D., and Ahmad, I. 2011. "Building Information Modeling for Sustainable Design and LEED ${ }^{\circledR}$ Rating Analysis." Automation in Construction 20: 217-24. http://dx.doi.org/10.1016/j. autcon.2010.09.019.

[15] Burg, R. G., and Ost, B. W. 1994. Engineering Properties of Commercially Available High-Strength Concretes (Including Three-Year Data). No. RD104. 02T.

[16] Liu, S. H., Li, L., H., and Feng, J. W. 2012. "Study on Mechanical Properties of Reactive Powder Concrete." Journal of Civil Engineering Construction 1 (1).

[17] Allena, S., and Newston, C. M. 2010. "Ultra-High Strength Concrete Mixtures Using Local Materials." Presented at 2010 Concrete Sustainability Conference, New Mexico, 1-9.

[18] ASTM Standard C192-15. 2015. Standard Practice for Making and Curing Concrete Test Specimens in the Laboratory ASTM International, West Conshohocken, PA. DOI: 10.1520/C0192-15. www.astm.org.

[19] Shaheen, E., and Shrive, N. J. 2006. "Optimization of Mechanical Properties and Durability of Reactive Powder Concrete." ACI Materials Journal 103 (6): 444-51.

[20] BS EN 12390-3:2009. 2009. Testing Hardened Concrete-Compressive Strength of Test Specimens. B/517/1, p. 22.

[21] ASTM Standard C 39-15a. 2015. Standard Test Method for Compressive Strength of Cylindrical Concrete Specimens ASTM International, West Conshohocken, PA. DOI: 10.1520/C0192-15. www.astm.org. 